\section{JURNAL EKONOMI EFEKTIF}

ISSN : $2622-8882$, E-ISSN : 2622-9935

Jurnal Ekonomi Efektif, Vol. 3, No. 1, Oktober 2020 @ Prodi Manajemen Fakultas Ekonomi Universitas Pamulang

\title{
PENGARUH KUALITAS PRODUK TERHADAP KEPUTUSAN PEMBELIAN KEWPIE SALAD DRESSING PADA PT. KEWPIE INDONESIA
}

\author{
Agus Sudarsono $^{1 *}$, Mitri Nelsi ${ }^{2}$, Hasanudin $^{3}$ \\ Universitas Pamulang \\ dosen02473@unpam.ac.id*
}

\begin{abstract}
ABSTRAK
Penelitian ini bertujuan untuk mengetahui pengaruh kualitas produk terhadap keputusan pembelian Kewpie Salad Dressing Pada PT. Kewpie Indonesia. Metode yang digunakan adalah explanatory research dengan sampel sebanyak 96 responden. Teknik analisis menggunakan analisis statistik dengan pengujian regresi, korelasi, determinasi dan uji hipotesis. Hasil penelitian ini variabel kualitas produk diperoleh nilai rata-rata skor sebesar 3,41 dengan kriteria baik. Variabel keputusan pembelian diperoleh nilai rata-rata skor sebesar 3,83 dengan kriteria baik. Kualitas produk berpengaruh positif dan signifikan terhadap keputusan pembelian dengan nilai persamaan regresi $\mathrm{Y}=9,141+0,857 \mathrm{X}$, dan nilai koefisien korelasi 0,780 atau memiliki tingkat hubungan yang kuat dengan nilai determinasi $60,9 \%$. Uji hipotesis diperoleh signifikansi $0,000<0,05$.
\end{abstract}

\section{Kata Kunci: Kualitas Produk, Keputusan Pembelian.}

\section{ABSTRACT}

This study aims to determine the effect of product quality on purchasing decisions of Kewpie Salad Dressing at PT. Kewpie Indonesia. The method used is explanatory research with a sample of 96 respondents. The analysis technique uses statistical analysis with regression testing, correlation, determination and hypothesis testing. The results of this research variable product quality obtained an average score of 3.41 with good criteria. The purchase decision variable obtained an average score of 3.83 with good criteria. Product quality has a positive and significant effect on purchasing decisions with the regression equation value $Y=9.141+0.857 X$, and a correlation coefficient value of 0.780 or has a strong level of relationship with a determination value of 60.9\%. Hypothesis testing obtained a significance of $0.000<0.05$.

Keywords: Product Quality, Purchasing Decision. 


\section{PENDAHULUAN}

\section{A. Latar Belakang Masalah}

Dewasa ini trend gaya hidup masyarakat semakin memilih pada hal-hal yang dirasakan simpel dan cepat dalam penyajiannya. Tentu kondisi ini tidak hanya terkait dengan sandang namun juga makanan. Pemerintah melalui dinas kesehatan sedang giatnya melakukan sosialisai tentang pola hidup sehat yang didukung oleh keterlibatan media iklan maupun sosial dalam menyampaikanya. Oleh karena itu, masyarakat Jakarta sekarang telah menyadari betapa pentingnya berolahraga dan menjalankan pola makan untuk hidup yang lebih sehat.

Seiring perkembangan zaman, banyak sekali varian makanan sehat yang di buat. Salah satunya adalah salad. Salad adalah makanan sehat yang terbuat dari sayuran dan buah-buahan yang di lengkapi dengan saus salad atau biasa disebut Dressing. Di Indonesia sejak dulu sudah ada yang namanya rujak dan pecel, namun seiring berjalannya waktu, terdapat inovasi yang berkembang dengan menciptakan produk untuk saus siram salad.

Banyak ditemukan produk-produk saus salad disupermarket, dari mulai yang impor, lokal, hingga produk impor yang sudah memiliki pabrik di Indonesia. Hal ini disebabkan pula oleh perilaku konsumen yang ingin mengkonsumsi sayuran atau buah dengan menggunakan saus salad secara mudah dan cepat.

Perilaku konsumen pada hakikatnya untuk memahami "mengapa konsumen melakukan dan apa yang mereka lakukan". Schiffman dan Kanuk (2008:6) mengemukakan bahwa studi perilaku konsumen adalah suatu studi bagaimana seorang individu membuat keputusan untuk mengalokasikan sumber daya yang tersedia. Makan makanan sehat seperti salad membuat bahagia bagi para penggemar salad, karena mendapatkan manfaat bagi kesehatan tubuhnya. Apalagi dengan saus salad yang beragam merek dan rasa sesuai selera konsumen.

Persaingan yang ketat dalam berbagai merek produk saus salad yang dijual di supermarket, membuat para pebisnis saus salad berlomba-lomba menciptakan varian yang digemari konsumenya. Contoh merk lokal ialah Mamasuka dan Maestro sedangkan contoh merk impor ialah Remia dan Helmans. Masuknya produk luar negeri yang dikelola secara professional agar dapat bersaing untuk memperebutkan konsumen di bisnis saus siram salad. Dengan menciptakan rasa yang memanjakan lidah dan kualitas produk yang bagus merupakan salah satu cara merebut hati konsumen untuk menjadi pelanggannya, serta membangun citra yang baik dimata konsumen. Citra dapat mempengaruhi proses keputusan pembelian produk, oleh karena itu citra menjadi faktor penting bagi keberhasilan pemasaran suatu produk.

Persaingan bisnis merupakan persaingan yang harus dihadapi oleh perusahaan. Persaingan yang semakin ketat ini menuntut perusahaan saus salad untuk lebih cermat dalam menentukan strategi pemasaran agar dapat memenangkan persaingan yang dihadapi. Agar dapat keluar dari situasi yang mengancam kehidupan perusahaan, maka manajemen perusahaan dituntut untuk menciptakan rasa dan mengimplementasikan dengan menu-menu baru. Menggunakan menu-menu baru dengan saus salad merupakan satu dari sekian banyaknya strategi pemasaran yang mampu menciptakan, mempertahankan, dan meningkatkan kepuasan konsumen. Pada akhirnya, strategi tersebut dapat menciptakan suatu kesetiaan konsumen terhadap perusahaan.

Kualitas produk menjadi faktor penting dalam mempengaruhi perilaku konsumen untuk melakukan pembelian ulang produk salad dressing. Mengingat perkembangan bisnis sangat pesat dan banyaknya peluang untuk memasuki bisnis salad dressing, maka studi tentang citra merek salad dressing sangat diperlukan untuk mengukur daya saing 
dipasaran. PT. Kewpie Indonesia selalu berupaya menciptakan rasa melalui penampilan citra merek yang baik.

PT. Kewpie Indonesia berkomitmen untuk menciptakan produk-produk yang berkualitas dengan SOP nya, produk memiliki arti penting bagi perusahaan karena tanpa adanya produk, perusahaan tidak akan dapat melakukan apapun dari usahanya. Pembeli akan membeli produk kalau merasa cocok, karena itu produk harus disesuaikan dengan keinginan ataupun kebutuhan pembeli agar pemasaran produk berhasil. Dengan kata lain, pembuatan produk lebih baik diorentasikan pada keinginan pasar atau selera konsumen. Kotler (2005:49),"Kualitas produk adalah keseluruhan ciri serta dari suatu produk atau pelayanan pada kemampuan untuk memuaskan kebutuhan yang dinyatakan atau tersirat". Sedangkan menurut Lupiyoadi (2001:158) menyatakan bahwa "Konsumen akan merasa puas bila hasil evaluasi mereka menunjukan bahwa produk yang mereka gunakan berkualitas".

Kewpie Indonesia adalah perusahaan yang bergerak dibidang manufacturing makanan, dalam hal ini adalah saus dressing dan mayonnaise serta olahan telur. Perusahan Kewpie sudah berdiri sejak 100 tahun lalu di Jepang dan mulai membangun bisnis tahun 2013 di Indonesia. Dengan sertifikat halal dan NKV, Kewpie Indonesia menyediakan produk makanan halal, aman serta berkualitas untuk masyarakat Indonesia. Produk-produk PT. KEWPIE INDONESIA tahun 2016 memperoleh sertifikat FSSSC 22000 dan ISO 22000:2005, yang merupakan system manajemen keamanan pangan untuk seluruh rantai produksi pangan yang berlaku secara internasional.

Dengan banyaknya perusahaan yang bergerak dibidang yang sama dan juga banyak produk impor yang masuk ke Indonesia, maka PT Kewpie Indonesia memiliki banyak sekali kompetitor seperti MAESTRO dari Mamasuka Indonesia, REMIA produk Jerman dan masih banyak lagi, untuk lebih jelasnya dapat dilihat pada tabel berikut.

Tabel 1. Daftar Produk PT. Kewpie Indonesia Salad Dressing dan Produk Kompetitor

\begin{tabular}{|c|c|c|c|}
\hline No & Nama produk & Item produk & Berat \\
\hline \multirow[t]{5}{*}{1.} & KEWPIE & Wijen Sangria & $200 \mathrm{ml}$ \\
\hline & & Thousand Island & $200 \mathrm{ml}$ \\
\hline & & Caesar & $200 \mathrm{ml}$ \\
\hline & & Kecap ala Jepang & $200 \mathrm{ml}$ \\
\hline & & Tomat pedas & $200 \mathrm{ml}$ \\
\hline \multirow[t]{2}{*}{2.} & MAMASUKA & Thousand Island & $300 \mathrm{~g}$ \\
\hline & & Cheesy mayonnaise & $300 \mathrm{~g}$ \\
\hline \multirow[t]{8}{*}{3.} & REMIA & Thousand Island & $250 \mathrm{ml}$ \\
\hline & & Italian dressing & $250 \mathrm{ml}$ \\
\hline & & Caesar & $250 \mathrm{ml}$ \\
\hline & & Blue cheese & $250 \mathrm{ml}$ \\
\hline & & French dressing & $250 \mathrm{ml}$ \\
\hline & & Garlic & $250 \mathrm{ml}$ \\
\hline & & Yogurt dressing & $250 \mathrm{ml}$ \\
\hline & & Honey dressing & $250 \mathrm{ml}$ \\
\hline 4. & HELMANS & Honey mustard & $180 \mathrm{ml}$ \\
\hline 5. & MIZKAN & Wijen sangrai & $200 \mathrm{ml}$ \\
\hline \multirow[t]{2}{*}{6.} & KUHNE & Thousand Island & $250 \mathrm{ml}$ \\
\hline & & Caesar & $250 \mathrm{ml}$ \\
\hline \multirow[t]{2}{*}{7.} & MAESTRO & Thousand Island & $237 \mathrm{ml}$ \\
\hline & & Blue cheese & $237 \mathrm{ml}$ \\
\hline \multirow[t]{2}{*}{8.} & AISAMURAKI & Sesame & $200 \mathrm{ml}$ \\
\hline & & Black sesame & $200 \mathrm{ml}$ \\
\hline \multirow[t]{2}{*}{9.} & KRAFT & Thousand Island & $475 \mathrm{ml}$ \\
\hline & & Blue cheese & $475 \mathrm{ml}$ \\
\hline
\end{tabular}

Sumber : Supermarket Ranch Grand Indonesia, 2019 
Dari data diatas, walaupun memiliki pesaing yang banyak, PT Kewpie Indonesia memiliki strategi untuk mempertahankan eksistensinya sebagai produk makanan salad dressing yang digemari konsumenya. Penjualan produk PT Kewpie Indonesia mengalami fluktuasi mulai dari tahun 2016 sampai dengan 2019.

Dibawah ini merupakan data penjualan dari PT Kewpie Indonesia salad dressing yang masih mengalami fluktuasi dan secara umum belum menguasai pasar produk sejenis.

Tabel 2. Data Penjualan PT. Kewpie Indonesia Periode Tahun 2017-2019

\begin{tabular}{|l|l|l|}
\hline \multicolumn{1}{|c|}{ Tahun } & \multicolumn{1}{c|}{ Penjualan $(\mathrm{Rp})$} & \multicolumn{1}{c|}{ Penjualan $(\mathrm{Rp})$} \\
\hline 2017 & 2.592 .263 .050 & 3.147 .762 .235 \\
\hline 2018 & 4.736 .057 .512 & 4.976 .421 .987 \\
\hline 2019 & 5.820 .431 .384 & 5.732 .685 .076 \\
\hline
\end{tabular}

Dari tabel diatas terlihat bahwa penjualan PT Kewpie Indonesia pada tiga tahun terakhir mengalami fluktuatif, disamping itu berdasarkan hasil pengamatan dilapangan terlihat strategi pemasaran yang dilakukan oleh perusahaan belum dapat memenuhi target yang diharapkan.

Namun demikian, citra merek Kewpie masih banyak yang belum mengetahui dan bagaimana kualitas produk serta cita rasa yang disajikan oleh kewpie salad dressing sehingga akan mendapatkan lebih banyak lagi konsumen yang mau mencoba kewpie.

Berdasarkan latar tersebut, maka peneliti bermaksud untuk melakukan penelitian tentang "Pengaruh kualitas produk terhadap keputusan pembelian Kewpie Salad Dressing Pada PT. Kewpie Indonesia".

\section{B. Rumusan Masalah}

1. Bagaimana kualitas produk Kewpie Salad Dressing Pada PT. Kewpie Indonesia ?.

2. Bagaimana keputusan pembelian Kewpie Salad Dressing Pada PT. Kewpie Indonesia ?.

3. Adakah pengaruh antara kualitas produk terhadap keputusan pembelian Kewpie Salad Dressing Pada PT. Kewpie Indonesia?.

\section{Tujuan Penelitian}

1. Untuk mengetahui kondisi kualitas produk Kewpie Salad Dressing Pada PT. Kewpie Indonesia.

2. Untuk mengetahui kondisi keputusan pembelian Kewpie Salad Dressing Pada PT. Kewpie Indonesia.

3. Untuk mengetahui pengaruh antara kualitas produk terhadap keputusan pembelian Kewpie Salad Dressing Pada PT. Kewpie Indonesia.

\section{METODE PENELITIAN}

\section{Populasi}

Populasi dalam penelitian ini berjumlah 96 responden PT. Kewpie Indonesia

2. Sampel

Teknik pengambilan sampling dalam penelitian ini adalah sampel jenuh, dimana semua anggota populasi dijadikan sebagai sampel. Dengan demikian sampel dalam penelitian ini berjumlah 96 responden.

\section{Jenis Penelitian}

Jenis penelitian yang dipakai adalah asosiatif, dimana tujuannya adalah untuk mengetahui mencari keterhubungan antara variabel independen terhadap variabel dependennya. 


\section{Metode Analisis Data}

Dalam menganalisis data digunakan uji validitas, uji reliabilitas, analisis regresi linier sederhana, koefisien korelasi, koefisien determinasi dan uji hipotesis.

\section{HASIL PENELITIAN DAN PEMBAHASAN}

\section{Analisis Deskriptif}

Pada pengujian ini digunakan untuk mengetahui skor minimum dan maksimum skor tertinggi, ratting score dan standar deviasi dari masing-masing variabel. Adapun hasilnya sebagai berikut:

Tabel 3. Hasil Analisis Descriptive Statistics

\section{Descriptive Statistics}

\begin{tabular}{|l|r|r|r|r|r} 
& N & Minimum & Maximum & Mean & \multicolumn{1}{c}{ Std. Deviation } \\
\hline Kualitas produk (X1) & 96 & 27 & 44 & 34.11 & 3.925 \\
\hline Keputusan pembelian (Y) & 96 & 29 & 49 & 38.39 & 4.312 \\
\hline Valid N (listwise) & 96 & & & & \\
\hline
\end{tabular}

Kualitas produk diperoleh varians minimum sebesar 27 dan varians maximum 44 dengan ratting score sebesar 3,411 dengan standar deviasi 3,925. Skor ini termasuk pada rentang sakala 3,40 - 4,19 dengan kriteria baik atau setuju.

Keputusan pembelian diperoleh varians minimum sebesar 29 dan varians maximum 49 dengan ratting score sebesar 3,839 dengan standar deviasi 4,312. Skor ini termasuk pada rentang sakala 3,40 - 4,19 dengan kriteria baik atau setuju.

\section{Analisis Verifikatif.}

Pada analisis ini dimaksudkan untuk mengetahui pengaruh variabel independen terhadap variabel dependen. Adapun hasil pengujian sebagai berikut:

\section{a. Analisis Regresi Linier Sederhana}

Uji regresi ini dimaksudkan untuk mengetahui perubahan variabel dependen jika variabel independen mengalami perubahan. Adapun hasil pengujiannya sebagai berikut:

Tabel 4. Hasil Pengujian Regresi Linier Sederhana Coefficients $^{\mathrm{a}}$

\begin{tabular}{|c|c|c|c|c|c|c|}
\hline \multirow{2}{*}{\multicolumn{2}{|c|}{ Model }} & \multicolumn{2}{|c|}{$\begin{array}{l}\text { Unstandardized } \\
\text { Coefficients }\end{array}$} & \multirow{2}{*}{$\begin{array}{c}\text { Standardized } \\
\text { Coefficients } \\
\text { Beta }\end{array}$} & \multirow[b]{2}{*}{$\mathrm{t}$} & \multirow[b]{2}{*}{ Sig. } \\
\hline & & $\mathrm{B}$ & Std. Error & & & \\
\hline \multirow[t]{2}{*}{1} & (Constant) & 9.141 & 2.434 & & 3.756 & .000 \\
\hline & Kualitas Produk (X) & .857 & .071 & .780 & 12.095 & .000 \\
\hline
\end{tabular}

a. Dependent Variable: Keputusan Pembelian (Y)

Berdasarkan hasil pengujian pada tabel di atas, diperoleh persamaan regresi $\mathrm{Y}$ $=9,141+0,857 \mathrm{X}$. Dari persamaan tersebut dijelaskan sebagai berikut:

1) Konstanta sebesar 9,141 diartikan jika kualitas produk tidak ada, maka telah terdapat nilai keputusan pembelian sebesar 9,141 point.

2) Koefisien regresi kualitas produk sebesar 0,857 , angka ini positif artinya setiap ada peningkatan kualitas produk sebesar 0,857 point maka keputusan pembelian juga akan mengalami peningkatan sebesar 0,857 point.

\section{b. Analisis Koefisien Korelasi}

Analisis koefisien korelasi dimaksudkan untuk mengetahui tingkt kekuatan hubungan dari variabel independen terhadap variabel dependen. Adapun hasil pengujian sebagai berikut: 
Tabel 5. Hasil Pengujian Koefisien Korelasi Kualitas produk Terhadap Keputusan pembelian. Correlations $^{\text {b }}$

\begin{tabular}{llr|r} 
& & $\begin{array}{c}\text { Kualitas } \\
\text { Produk }(\mathrm{X})\end{array}$ & $\begin{array}{c}\text { Keputusan } \\
\text { Pembelian }(\mathrm{Y})\end{array}$ \\
\hline Kualitas produk $(\mathrm{X})$ & Pearson Correlation & 1 & $.780^{* *}$ \\
\cline { 2 - 4 } & Sig. (2-tailed) & & .000 \\
\hline Keputusan Pembelian (Y) & Pearson Correlation & $.780^{* *}$ & 1 \\
\cline { 2 - 4 } & Sig. (2-tailed) & .000 & \\
\hline
\end{tabular}

${ }^{\star *}$. Correlation is significant at the 0.01 level (2-tailed).

b. Listwise $\mathrm{N}=96$

Berdasarkan hasil pengujian diperoleh nilai korelasi sebesar 0,780 artinya kualitas produk memiliki hubungan yang kuat terhadap keputusan pembelian.

\section{c. Analisis Koefisien Determinasi}

Analisis koefisien determinasi dimaksudkan untuk mengetahui besarnya persentase pengaruh dari variabel independen terhadap variabel dependen. Adapun hasil pengujian sebagai berikut:

Tabel 6. Hasil Pengujian Koefisien Determinasi Kualitas produk Terhadap Keputusan pembelian.

\section{Model Summary}

\begin{tabular}{l|c|cr|r} 
& & \multicolumn{2}{c}{$\begin{array}{c}\text { Adjusted R } \\
\text { Model }\end{array}$} & \multicolumn{2}{c}{$\begin{array}{c}\text { Std. Error of the } \\
\text { Estimate }\end{array}$} \\
\hline 1 & R Square & .609 & 2.712 \\
\hline a. Predictors: (Constant), Kualitas Produk $(\mathrm{X})$ & & .605 &
\end{tabular}

Berdasarkan hasil pengujian diperoleh nilai determinasi sebesar 0,609 artinya kualitas produk memiliki kontribusi pengaruh sebesar 60,9\% terhadap keputusan pembelian.

\section{d. Uji Hipotesis}

Pengujian hipotesis dengan uji t digunakan untuk mengetahui hipotesis mana yang diterima.

Rumusan hipotesis: Terdapat pengaruh yang signifikan antara kualitas produk terhadap keputusan pembelian.

Tabel 7. Hasil Uji Hipotesis Kualitas produk Terhadap Keputusan pembelian.

\section{Coefficients $^{a}$}

\begin{tabular}{|c|c|c|c|c|c|c|}
\hline \multirow{2}{*}{\multicolumn{2}{|c|}{ Model }} & \multicolumn{2}{|c|}{$\begin{array}{l}\text { Unstandardized } \\
\text { Coefficients }\end{array}$} & \multirow{2}{*}{$\begin{array}{c}\text { Standardized } \\
\text { Coefficients } \\
\text { Beta } \\
\end{array}$} & \multirow[b]{2}{*}{$\mathrm{t}$} & \multirow[b]{2}{*}{ Sig. } \\
\hline & & $\mathrm{B}$ & Std. Error & & & \\
\hline 1 & (Constant) & 9.141 & 2.434 & & 3.756 & .000 \\
\hline & Kualitas Produk (X) & .857 & .071 & .780 & 12.095 & .000 \\
\hline
\end{tabular}

a. Dependent Variable: Keputusan Pembelian (Y)

Berdasarkan hasil pengujian pada tabel di atas, diperoleh nilai $t$ hitung $>\mathrm{t}$ tabel atau $(12,095>1,986)$, dengan demikian hipotesis yang diajukan bahwa terdapat pengaruh yang signifikan atara kualitas produk terhadap keputusan pembelian diterima.

\section{PEMBAHASAN HASIL PENELITIAN}

\section{Kondisi Jawaban Responden Variabel Kualitas Produk}

Berdasarkan jawaban responden, variabel kualitas produk diperoleh ratting score sebesar 3,411 berada di rentang skala 3,40 - 4,19 dengan kriteria baik atau setuju.

2. Kondisi Jawaban Responden Variabel Keputusan Pembelian

Berdasarkan jawaban responden, variabel keputusan pembelian diperoleh ratting score 
sebesar 3,839 berada di rentang skala 3,40 - 4,19 dengan kriteria baik atau setuju.

\section{Pengaruh Kualitas Produk Terhadap Keputusan Pembelian}

Kualitas produk berpengaruh signifikan terhadap keputusan pembelian dengan persamaan regresi $\mathrm{Y}=9,141+0,857 \mathrm{X}$, nilai korelasi sebesar 0,780 atau memiliki hubungan yang kuat dengan kontribusi pengaruh sebesar 60,9\%. Pengujian hipotesis diperoleh nilai t hitung $>\mathrm{t}$ tabel atau $(12,095>1,986)$. Dengan demikian hipotesis yang diajukan bahwa terdapat berpengaruh signifikan antara kualitas produk terhadap keputusan pembelian diterima.

\section{PENUTUP}

\section{Kesimpulan}

a. Variabel kualitas produk diperoleh ratting score sebesar 3,411 berada di rentang skala 3,40 - 4,19 dengan kriteria baik atau setuju.

b. Variabel keputusan pembelian diperoleh ratting score sebesar 3,839 berada di rentang skala 3,40 - 4,19 dengan kriteria baik atau setuju.

c. Kualitas produk berpengaruh signifikan terhadap keputusan pembelian dengan persamaan regresi $\mathrm{Y}=9,141+0,857 \mathrm{X}$, nilai korelasi sebesar 0,780 atau kuat dan kontribusi pengaruh sebesar $60,9 \%$ sedangkan sisanya sebesar $39,1 \%$ dipengaruhi faktor lain. Uji hipotesis diperoleh nilai thitung > t tabel atau $(12,095>1,986)$.

\section{Saran}

a. Perusahaan harus mampu memproduksi varian produk yang beragam yang tetap menjaga mutu produk tetap halal dan enak dikonsumsi

b. Perusahaan harus selalu memberikan informasi baik melalui kegiatan sosial dan kegiatan pemasaran lainnya terkait dengan pengenalan produk agar lebih dikenal dimasyarakat

\section{DAFTAR PUSTAKA}

Arikunto, Suharsimi (2014). “Prosedur Penelitian Suatu Pendekatan Praktek”. Jakarta: Rineka Cipta.

Basu Swastha Dharmmesta. (2014). Manajemen Pemasaran. BPFE: Yogyakarta.

Bilson Simamora (2016) Panduan Riset Prilaku Konsumen, Jakarta: PT. Gramedia Pustaka.

Fandy Tjiptono (2017), Serivce Quality and Satisfiation. Jakarta: Edisi tiga. Andi.

Freddy Rangkuti (2016) Strategi Promosi Yang Kreatif, Edisi Pertama, Cetakan Pertama Jakarta: Gramedia Pustaka Utama.

Jasmani, J. (2018). Pengaruh Kualitas Produk Dan Harga Terhadap Keputusan Pembelian Pada PT. Baja Mandiri Di Jakarta. Disrupsi Binis, 1(1).

Jasmani, J., \& Sunarsi, D. (2020). The Influence of Product Mix, Promotion Mix and Brand Image on Consumer Purchasing Decisions of Sari Roti Products in South Tangerang. PINISI Discretion Review, 1(1), 165-174.

Kharis, Ismu Fadli (2011). "Studi Mengenai Impulse Buying dalam Penjualan Online”. Semarang : Skripsi Universitas Diponegoro

Kotler dan Amstrong (2017), Prinsip-prinsip Pemasaran. Edisi Kedua Belas”. Jilid Satu. Jakarta: Erlangga.

Lupiyoadi (2016) Manajemen Pemasaran Jasa, Edisi 4, Jakarta: Salemba Empat.

Prasada, D., Sunarsi, D., \& Teriyan, A. (2020). Pengaruh Etos Kerja Dan Kompensasi Terhadap Komitmen Organisasi Pada DHL Logistic Di Jakarta. JENIUS (Jurnal Ilmiah Manajemen Sumber Daya Manusia), 4(1), 51-60. 
Rao, Purba, (2012). “Measuring Consumer Perceptions Through Factor Analysis”, The Asian.

Santoso, Singgih (2015). "Menguasai Statistik Multivariat". Jakarta: PT Elex Media Komputindo.

Sugiyono (2017), "Metode Penelitian Administrasi : dilengkapi dengan Metode $R \&$ D”. Bandung: Alfabeta.

Suhartanto (2014). "Metode Riset Pemasaran". Bandung: Alfabeta

Sunarsi, D. (2019). Pengaruh Kompetensi, Pengembangan Karir dan Lingkungan Kerja Terhadap Kepuasan Kerja Karyawan Pada PT. Boga Lestari Sentosa Indonesia (Kenny Rogers Roasters).

Sunarsi, D., \& Baharuddin, A. (2019). The Effect of Service Quality and Price Accuracy on Consumer Confidence and Implications for Sales Increase. PINISI Discretion Review, 3(2), 101-110.

Sunarsi, D., Winata, H., Gunartin, G., \& Paeno, P. (2020). Analisis Gaya Kepemimpinan Kepala Desa Dalam Pengembangan Desa Cidokom Gunung Sindur Kabupaten Bogor. Jurnal Ekonomi Efektif, 2(3).

Yusuf, A. D Sunarsi. (2020). The Effect of Promotion and Price on Purchase Decisions. Almana: Jurnal Manajemen dan Bisnis 4 (2), 272-279 